\title{
Proteomic analysis of mucosal preparations from patients with ulcerative colitis
}

\author{
FRANZ FOGT $^{1}$, BO JIAN ${ }^{1}$, RENE C. KRIEG ${ }^{2}$ and AXEL WELLMANN ${ }^{3}$ \\ ${ }^{1}$ Department of Pathology, Penn Presbyterian Medical Center, University of Pennsylvania, \\ Philadelphia, PA 19104, USA; ${ }^{2}$ Institute of Pathology, RWTH Aachen University, \\ D-52074 Aachen; ${ }^{3}$ Pathologisches Institut Celle, D-29223 Celle, Germany
}

Received October 29, 2007; Accepted December 3, 2007

\begin{abstract}
Proteomic profiling with the identification of molecular signatures is a powerful tool in the study of pathogenesis, and may allow us to predict the prognosis of disease states. In this study, mucosa/submucosa from the colonic resections of five patients with ulcerative colitis (UC) who had undergone colonic resection were microdisected. Proteins were separated by two-dimensional (2D) polyacrylamide gel electrophoresis. Proteins of interest were further extracted and identified by tryptic in-gel digestion and mass spectrometry. Among the proteins found were ones associated with inflammation and tissue repair, namely protocadherin, $\alpha-1$ antitrypsin, tetratricopeptide repeat domains and caldesmon. Surprisingly, in all five cases specific spots were identified that represented mutated forms of desmin expressed in UC mucosa/submucosa (two spots were sequenced) and were verified with Western blotting. In summary, proteomic signature profiles of UC represent proteins associated with inflammation and repair. Mutated desmin may represent a specific protein associated with UC and may be used in the differential diagnosis of forms of inflammatory bowel disease (IBD).
\end{abstract}

\section{Introduction}

Ulcerative colitis (UC) and Crohn's disease are inflammatory diseases of the colon and of the entire gastrointestinal tract, respectively. Recent studies indicate that the incidence of Crohn's disease and UC is approximately 5 out of 100,000 , respectively. Risk factors for the development of inflammatory bowel disease (IBD) include environmental and, possibly, genetic factors. It has been shown that the risk of developing Crohn's disease is increased 35 times in the first-degree relatives of patients with Crohn's disease, and the risk of UC

Correspondence to: Dr Franz Fogt, Department of Pathology, Penn Presbyterian Medical Center, University of Pennsylvania, 39th and Market Streets, Philadelphia, PA 19104, USA

E-mail: franz.fogt@uphs.upenn.edu

Key words: ulcerative colitis, proteomics, desmin, inflammation is increased 15 times in first-degree relatives of UC patients. Linkage disequilibrium studies of multiple families have shown changes in chromosome 16 at the level of the NOD2 gene, which may be associated with inappropriate reactions to endogenous gastrointestinal bacteria (1). In patients with UC, an association with HLA class II haplotypes has been identified. Few studies have analyzed tissue derived from patients with IBD using proteomic techniques. Proteomic studies are a powerful tool for the analysis of genetic transcription studies that assess gene expression on the protein level. In this study, the analyzed proteomic profile of bowel mucosa from patients with UC was analyzed, and the sequence of the differentially-expressed protein identified.

\section{Materials and methods}

We selected five cases of total colectomy in patients with UC. The diagnosis of UC was made based on clinical presentation, endoscopic evaluation, biopsy, history and an evaluation of the surgical pathology specimens. The specimens were opened fresh, without fixation, and the mucosal/submucosal - but not the muscularis propria - was removed and placed in a container filled with OMTC.

Specimens collected included grossly involved colon by $\mathrm{UC}$ and uninvolved colon or small intestinal mucosa. The container was closed and stored at $-80^{\circ} \mathrm{C}$ until processing for microdissection. All specimens were submitted to Transmedix Corp., Rockville, MD, for further processing and analysis. Tissue epithelium was microdissected based on its histological evaluation.

Two-dimensional SDS-PAGE. Each dissected tissue was collected in $30 \mu \mathrm{l}$ extraction buffer II containing $8 \mathrm{M}$ urea, 4\% (w/v) CHAPS, $40 \mathrm{mM}$ Tris, 0.2\% (w/v) Bio-Lyte 3/10 (4/7) and $2 \mathrm{mM}$ tributyl phosphine (Bio-Rad, Hercules, CA), vortexed vigorously at room temperature for $60 \mathrm{~min}$ and centrifuged in a microcentrifuge at $12,000 \mathrm{rpm}$ for $15 \mathrm{~min}$. The supernatant was assayed for its protein concentration using the RC DC protein assay kit I (Bio-Rad) and the SmartSpec 3000 (Bio-Rad). Protein lysate $(100 \mu \mathrm{g})$ was combined with rehydration Buffer (Bio-Rad) containing $8 \mathrm{M}$ urea, $2 \%$ CHAPS, $50 \mathrm{mM}$ DTT and 0.2\% (w/v) Bio-Lyte 3/10 (4/7) ampholytes, to a final volume of $185 \mu 1$ before isoeletric focusing. 
The first dimension of 2D electrophoresis was performed on a Protean IEF System (Bio-Rad) with each ReadyStrip IPG strip ( $\mathrm{pH} 4.0-7.0,11 \mathrm{~cm}$ ) (Bio-Rad) rehydrated with $185 \mu 1$ of sample for $12 \mathrm{~h}$ and subsequently subjected to high voltages at $20^{\circ} \mathrm{C}$ for electric focusing of $250 \mathrm{~V}$ for $20 \mathrm{~min}, 8,000 \mathrm{~V}$ for $2 \mathrm{~h}$ and $30 \mathrm{~min}$ and a final step of $25,000 \mathrm{Vh}$. IPG strips were washed in rehydration buffer I containing $6 \mathrm{M}$ urea, $2 \%$ SDS, $375 \mathrm{mM}$ Tris- $\mathrm{HCl}$ (pH 8.8), $20 \%$ glycerol, and 2\% (w/v) DTT and in buffer II containing $6 \mathrm{M}$ urea, 2\% SDS, $375 \mathrm{mM}$ Tris$\mathrm{HCl}(\mathrm{pH} 8.8), 20 \%$ glycerol and $2.5 \%(\mathrm{w} / \mathrm{v})$ iodoacetamide (Bio-Rad), for 10 min each. Criterion Precast Gels (8-16\% Tris- $\mathrm{HCl}, 1.0 \mathrm{~mm}$ ) (Bio-Rad) were used for the second dimension of protein separation in a Criterion Dodeca cell (Bio-Rad) under a constant voltage of $200 \mathrm{~V}$ for $55 \mathrm{~min}$. Gels were stained with the Silver Stain Plus kit (Bio-Rad). The staining procedure was based on methods developed by Gottlieb and Chavko (Gottlieb, 1987 \#12) in which no oxidization of proteins takes place and silver ions transfer from tunstosillic acid to the proteins in the gel by means of an ion exchange or electrophilic process. Methanol and acetic acid needed for fixing the gels were purchased from Sigma-Aldrich (St. Louis, MO).

Image analysis. Gel images were captured using a digital camera, and spots from normal and UC colon 2D/PAGE analysis were compared using Adobe Photoshop and Melanie Viewer softwares, respectively. Candidate spots displaying differential intensity between two gel images were excised for mass spectrometric analysis.

In-gel digestion. Protein spots of interest were excised from the gel, placed in clean $0.5 \mathrm{ml}$ Eppendorf tubes and stored at $-20^{\circ} \mathrm{C}$. Silver-stained spots were destained. After destaining, individual protein gel spots were subjected to reduction and alkylation, followed by in situ digestion with trypsin. The resulting peptide mixtures were recovered by sequential extraction and dried to near completion in a vacuum centrifuge, then diluted to a $10 \mu \mathrm{l}$ final volume in $5 \% \mathrm{CH}_{3} \mathrm{CN}$, $0.1 \% \mathrm{HCO}_{2} \mathrm{H}$.

Mass spectrometry. Peptides from in-gel digests were analyzed by capillary LC-MS/MS. An LC10VP series HPLC system (Shimadzu Scientific Instruments Inc., Columbia, MD) was interfaced with an LCQ ion trap mass spectrometer (ThermoFinnigan, San Jose, CA). Reversed phase HPLC was carried out using a PicoFrit microbore column $(0.075 \times 100 \mathrm{~mm}$; New Objective Inc., Woburn, MA) packed with $10 \mathrm{~cm}$ of BetaBasic 18 resin (Thermo Hypersil-Keystone, Bellefonte, PA) installed on the New Objective PicoView mounting system. The HPLC system was operated at $15 \mu \mathrm{l} / \mathrm{min}$ and the flow was split to approximately $200 \mathrm{nl} / \mathrm{min}$ using a 1,000 psi back pressure regulator (Upchurch Scientific, Oak Harbor, WA). Mobile phase A was $\mathrm{H}_{2} \mathrm{O}: \mathrm{CH}_{3} \mathrm{CN}: \mathrm{HCO}_{2} \mathrm{H}$ (94.9:5:0.1) and mobile phase $\mathrm{B}$ was $\mathrm{H}_{2} \mathrm{O}: \mathrm{CH}_{3} \mathrm{CN}: \mathrm{HCO}_{2} \mathrm{H}$ (19.9:80:0.1). The chromatograph was developed using a linear gradient from $10 \% \mathrm{~B}$ to $60 \% \mathrm{~B}$ over $40 \mathrm{~min}$. The LCQ was set to iteratively acquire a full MS scan between 400 and $1,800 \mathrm{~m} / \mathrm{z}$, followed by full MS/MS scans of the five most abundant ions from the preceding MS scan. Relative collision energy for collisioninduced dissociation was set to $35 \%$, with a $30-\mathrm{msec}$ activation
$\mathbf{A}$

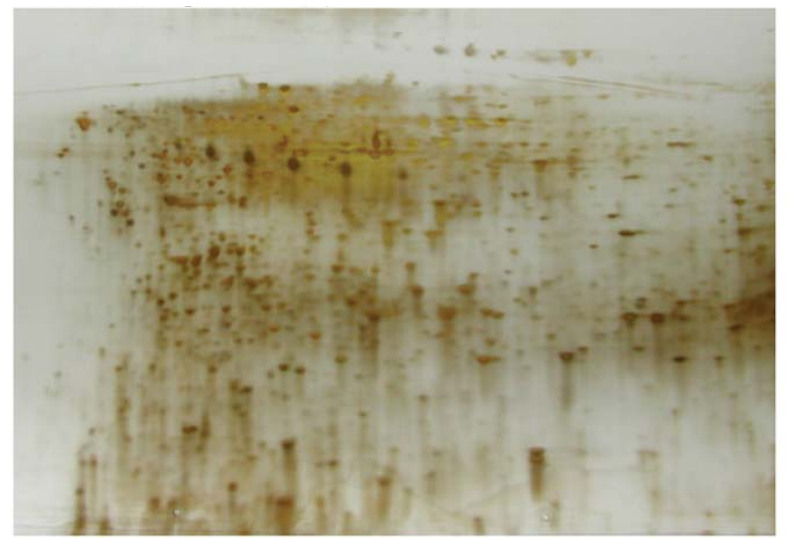

B

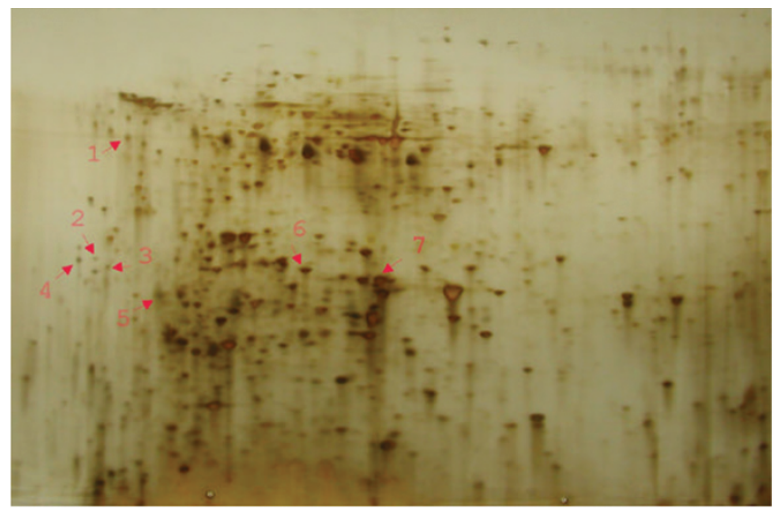

Figure 1. (A) Normal colon epithelium. 2D electrophoresis of the normal colon in patients with UC for proteomic analysis. (B) UC colon epithelium. While most protein spots appear common in both normal and abnormal epithelia proteomes, spots displaying differential intensity in either of the gel images could be identified under a Melanie Viewer.

time. Dynamic exclusion was enabled with a repeat count of 2 , a repeat duration of $0.5 \mathrm{~min}$ and a 1 -min exclusion duration window.

Protein identification. Unprocessed data files containing MS/MS spectra were submitted to the Mascot search engine (MatrixScience Ltd., London, UK) for database searching using the Mascot daemon. Mascot compares the mass values of observed product ions with the mass values calculated for theoretical product ions from peptide sequences present in a specified genomic database. From this comparison a probability-based score is calculated which reflects the statistical significance of the match between the product ion spectrum and the sequences contained in a database. The SwissProtTrembl database was searched using Homo sapiens as a taxonomic restrictor.

Western blot analysis. Eighty micrograms of protein lysate extracted from each microdissected tissue was denatured and loaded on a Criterion 8-16\% Tris 18-well gel (Bio-Rad) for SDS-PAGE and were further blotted onto a $8.5 \times 13.5 \mathrm{~cm}$ immunoblot filter (Bio-Rad) with the Criterion Blotter/Plate Electrodes (Bio-Rad). Rabbit anti-desmin (1:2,000; Chemicon International, Inc.) and anti- $\beta$-actin (1:4,000; Abcam, Inc., Cambridge, MA) were used for binding desmin and $B$-actin 
Table I. A set of proteins identified by LC-MS/MS.

\begin{tabular}{|c|c|c|c|}
\hline Spot & IPI no. & Score & Protein identification \\
\hline 1 & & & Protocadherin 17 precursor (protocadherin 68) \\
\hline 2 & & & $\begin{array}{l}\alpha-1 \text {-antitrypsin precursor ( } \alpha-1 \text { protease inhibitor) } \\
\text { ( } \alpha-1 \text {-antiproteinase) }\end{array}$ \\
\hline 3 & & & Tetratricopeptide repeat domain 21B \\
\hline 4 & & & $\alpha-1$-antitrypsin (precursor) \\
\hline 5 & & & Caldesmon \\
\hline 6 & IPI00328108 & 105 & Mutant desmin \\
\hline 7 & IPI00293615 & 48 & Vesicular membrane protein P24 \\
\hline
\end{tabular}

Table II. Mutant desmin peptides detected in LC-MS/MS.

\begin{tabular}{lll}
\hline Peptide ID & \multicolumn{1}{c}{ Mutant peptide sequence } & No. of amino acid and mutation \\
\hline Q5RLN1 & ETSPEQRGSEVHTKKTVMIKTIETRD & No. 459 serine to isoleuine \\
GEVVIEATQQQHEVL (SEQ ID NO.1) & No. 468 valine to methionine \\
& ETSPEQRGSEVHTKKTVMIKTIETRDG \\
& EVVSEATQQQHEML (SEQ ID NO.2) & \\
\hline
\end{tabular}

antigens, respectively. A secondary antibody conjugated with horseradish peroxidase was further used for colorimetric detection with an Amplified OPTI-4CN detection kit (Bio$\mathrm{Rad})$.

\section{Results}

Patients. The specimens were obtained from 5 patients $(3$ females and 2 males) with a long-standing history of UC and an average age of 45.6 years (range 26-65). For all patients, there was previous biopsy evidence of $\mathrm{UC}$ and, at the time of the colectomy, diffuse inflammation of the colon which involved the entire colon in three cases, involvement up to the ascending colon in one case and involvement up to the sigmoid colon in one case. The pouch was followed in four patients without significant pathologic abnormalities, granuloma formation or the formation of fistulae.

Histological evaluation and microdissection. Colonic mucosa from subjects with UC was subjected to histological examination after staining with hematoxylin and eosin. Cells from normal epithelium and abnormal areas of the bowel were microdissected under a microscope for proteomic studies.

Two-dimensional SDS-PAGE. Individual proteins in lysate extracted from the microdissected normal and UC tissue of each UC patient were resolved on a $2 \mathrm{D}$ gel electrophoresis using a pH 4.0-7.0 IPG strip and an 8-16\% Tris-HCl PAGE. The resulting proteomes are shown in Fig. 1A (normal) and B (UC). While most protein spots appear common in normal and abnormal epithelia proteomes, spots displaying

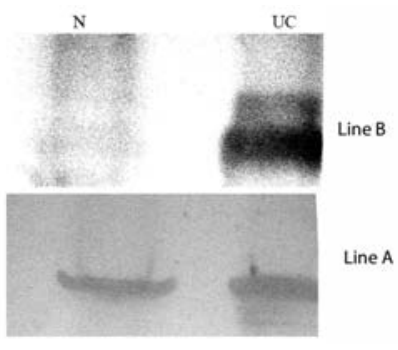

Figure 2. Desmin western blot analysis. A significant increase in the level of desmin protein can be observed in the UC sample (line B), which complies with the data observed in $2 \mathrm{D}$ gel analysis. Line A represents the level of $\beta$-actin as an internal control.

differential intensity in either of the gel images could be identified under a Melanie Viewer. A representative set of such spots (Fig. 1B, arrowed and numbered), displaying higher intensity in the UC-associated epithelium was excised for mass spectrometric analysis. The resulting protein identification is displayed in Table I. Among the seven spots identified, desmin was found to contain two mutant peptides in the mass spectrometric analysis (Table II).

Desmin Western blotting. To verify that colon UC-associated epithelial cells contain higher desmin protein levels than their normal epithelial counterparts, Western blot analysis targeting desmin antigen was performed. Anti- $\beta$-actin was used to ensure the equal loading of the lysates compared. As shown in Fig. 2A (desmin) and B ( $ß$-actin), a significant increase in desmin protein levels can be observed in the UC sample, which is in compliance with the data observed in the $2 \mathrm{D}$ gel analysis. 


\section{Discussion}

Proteomic profiling with the identification of molecular signatures is a powerful tool in the study of prognostic outcomes and the detection and selection of individual therapies. Proteomic analysis of signature proteins has been applied in tumor cell lines and solid tumors in an attempt to diagnose specific tumor subtypes $(2,3)$. In addition, proteomic signatures have been analyzed in the serum of patients with treated and untreated solid organ malignancies $(4,5)$. Proteomic analysis has also been used in an attempt to differentiate between inflammatory and neoplastic conditions of the pancreas, and with promising results (6). To date, few studies have addressed the proteomic signature profiles of patients with IBD. Such signature profiles may increase insight into the etiology, diagnosis or treatment of IBD. In a recent study, proteomic analysis of cultured colon epithelial cells analyzed before and after exposure to interferons and inter-leukins revealed multiple induced cytokines and modulated proteins expressed in vitro (7). In this study, we performed 2D protein electrophoresis and analyzed representative protein spots which showed different expression between diseased tissue and uninvolved tissue epithelium. We specifically analyzed epithelial and lamina propria tissue in order to limit contamination from surrounding normal tissues. It appears that all the proteins with increased representation in the epithelium affected by UC in this study are associated with inflammation and repair mechanisms. Proto-cadherins are linked to the retention of the monolayer morphology of proliferating cells (8). High expression may serve to maintain orderly growth during the re-epithelialization process. $\alpha-1$ antitrypsin is a serine protease inhibitor (9) and is likely associated with proinflammatory cytokines, such as IL-1ß, IL-8, and with tumor necrosis factor $(10,11)$. Similarly, tetratricopeptide repeat domains, which are associated with heat shock proteins, are induced by several stress factors, including inflammation, and are in some cases associated with IBD (12).

The expression of Caldesmon and Desmin may mirror the increased proliferation of fibroblasts within the areas of the colon involved in UC (13-16).

The finding of desmin per se was therefore not an unexpected finding, but the presence of mutationally-altered desmin was surprising. Mutated desmin forms have been observed in desmin-related myopathies and cardiomyopathies, often with an associated interruption of the vimentin cytoskeleton and the accumulation of altered protein within the cells (17-19). It is likely that the finding represents a random mutation developing within a high turnover cell population, but we cannot entirely exclude the possibility that desmin mutation may be involved as a primary or secondary feature in the development or course of UC. Larger studies with expanded sequencing protocols are necessary to further analyze and define the relationship between mutated desmin and UC.

\section{Refernces}

1. Pierik M, Yang H, Barmada MM, Cavanaugh JA, Annese V, Brant SR, Cho JH, Duerr RH, Hugot JP, McGovern DP, PaavolaSakki P, Radford-Smith GL, Pavli P, Silverberg MS, Schreiber S, Taylor KD and Vlietinck R: IBD International Genetics Consortium. The IBD international genetics consortium provides further evidence for linkage to IBD4 and shows gene-environment interaction. Inflamm Bowel Dis 11: 1-7, 2005.
2. Perego RA, Bianchi C, Corizzato M, Eroini B, Torsello B, Valsecchi C, Di Fonzo A, Cordani N, Favini P, Ferrero S, Pitto M, Sarto C, Magni F, Rocco F and Mocarelli P: Primary cell cultures arising from normal kidney and renal cell carcinoma retain the proteomic profile of corresponding tissues. J Proteom Res 4: 1503-1510, 2005.

3. Seike M, Kondo T, Fujii K, Okano T, Yamada T, Matsuno Y, Gemma A, Kudoh S and Hirohashi S: Proteomic signatures for histological types of lung cancer. Proteomics 5: 2939-2948, 2005.

4. Kawakami T, Hoshida Y, Kanai F, Tanaka Y, Tateishi K, Ikenoue T, Obi S, Sato S, Teratani T, Shiina S, Kawabe T, Suzuki T, Hatano N, Taniguchi H and Omata M: Proteomic analysis of sera from hepatocellular carcinoma patients after radiofrequency ablation treatment. Proteomics 5: 4287-4895, 2005.

5. Berman DM, Shih IeM, Burke LA, Veenstra TD, Zhao Y, Conrads TP, Kwon SW, Hoang V, Yu LR, Zhou M, Kurman RJ, Petricoin EF and Liotta LA: Profiling the activity of $\mathrm{G}$ proteins in patient-derived tissues by rapid affinity-capture of signal transduction proteins (GRASP). Proteomics 4: 812-818, 2004 .

6. Crnogorac-Jurcevic T, Gangeswaran R, Bhakta V, Capurso G, Lattimore S, Akada M, Sunamura M, Prime W, Campbell F, Brentnall TA, Costello E, Neoptolemos J and Lemoine NR: Proteomic analysis of chronic pancreatitis and pancreatic adenocarcinoma. Gastroenterology 129: 1454-1463, 2005.

7. Barcelo-Batllori S, Andre M, Servis C, Levy N, Takikawa O, Michetti P, Reymond M and Felley-Bosco E: Proteomic analysis of cytokine induced proteins in human intestinal epithelial cells: implications for inflammatory bowel diseases. Proteomics 2: 551-560, 2002.

8. Okazaki N, Takahashi N, Kojima S, Masuho Y and Koga H: Protocadherin LKC, a new candidate for a tumor suppressor of colon and liver cancers, its association with contact inhibition of cell proliferation. Carcinogenesis 23: 1139-1148, 2002.

9. Carrell RW: alpha 1-Antitrypsin: molecular pathology, leukocytes, and tissue damage. J Clin Invest 78: 1427-1431, 1986.

10. Faust D, Raschke K, Hormann S, Milovic V and Stein J: Regulation of alpha1-proteinase inhibitor release by proinflammatory cytokines in human intestinal epithelial cells. Clin Exp Immunol 128: 279-284, 2002.

11. Wright JP, Young GO and Tigler-Wybrandi N: Predictors of acute relapse of Crohn's disease. A laboratory and clinical study. Dig Dis Sci 32: 164-170, 1987.

12. Stahl M, Ludwig D, Fellermann and Stange EF: Intestinal expression of human heat shock protein 90 in patients with Crohn's disease and ulcerative colitis. Dig Dis Sci 43: 1079-1087, 1998.

13. Nakayama H, Miyazaki E and Enzan H: Differential expression of high molecular weight caldesmon in colorectal pericryptal fibroblasts and tumour stroma. J Clin Pathol 52: 785-786, 1999.

14. Helfman DM, Levy ER, Berthier C, et al: Caldesmon inhibits nonmuscle cell contractility and interferes with the formation of focal adhesions. Mol Biol Cell 10: 3097-3112, 1999.

15. Arias MP and Pacaud M: Macrophage caldesmon is an actin bundling protein. Biochemistry 40: 12974-12982, 2001.

16. Scaife S, Brown R, Kellie S, Filer A, Martin S, Thomas AM, Bradfield PF, Amft N, Salmon M and Buckley CD: Detection of differentially expressed genes in synovial fibroblasts by restriction fragment differential display. Rheumatology 43: 1346-1352, 2004.

17. Bar H, Fischer D, Goudeau B, Kley RA, Clemen CS, Vicart P, Herrmann H, Vorgerd M and Schroder R: Pathogenic effects of a novel heterozygous R350P desmin mutation on the assembly of desmin intermediate filaments in vivo and in vitro. Hum Mol Genet 14: 1251-1260, 2005.

18. Pruszczyk P, Kostera-Pruszczyk A, Shatunov A, Goudeau B, Draminska A, Takeda K, Sambuughin N, Vicart P, Strelkov SV, Goldfarb LG and Kaminska A: Restrictive cardiomyopathy with atrioventricular conduction block resulting from a desmin mutation. Int J Cardiol 117: 244-253, 2007.

19. Park KY, Dalakas MC, Semino-Mora C, Lee HS, Litvak S, Takeda K, Ferrans VJ and Goldfarb LG: Sporadic cardiac and skeletal myopathy caused by a de novo desmin mutation. Clin Genet 57: 423-429, 2000. 